
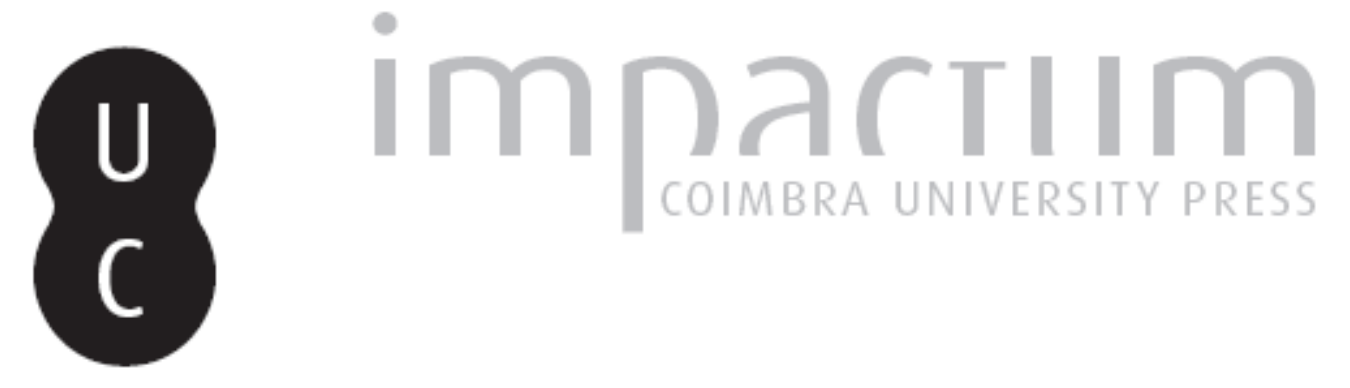

\title{
Leitura fenomenológica do texto medieval: a fauna de um país longínquo ou um pensamento universalmente singular?
}

\author{
Autor(es): $\quad$ Barbosa, Diogo Morais
}

Publicado por: Imprensa da Universidade de Coimbra

URL persistente:

URI:http://hdl.handle.net/10316.2/42824

DOI:

DOI:http://dx.doi.org/10.14195/0872-0851_48_1

Accessed : $\quad$ 26-Apr-2023 14:20:45

A navegação consulta e descarregamento dos títulos inseridos nas Bibliotecas Digitais UC Digitalis, UC Pombalina e UC Impactum, pressupõem a aceitação plena e sem reservas dos Termos e Condições de Uso destas Bibliotecas Digitais, disponíveis em https://digitalis.uc.pt/pt-pt/termos.

Conforme exposto nos referidos Termos e Condições de Uso, o descarregamento de títulos de acesso restrito requer uma licença válida de autorização devendo o utilizador aceder ao(s) documento(s) a partir de um endereço de IP da instituição detentora da supramencionada licença.

Ao utilizador é apenas permitido o descarregamento para uso pessoal, pelo que o emprego do(s) título(s) descarregado(s) para outro fim, designadamente comercial, carece de autorização do respetivo autor ou editor da obra.

Na medida em que todas as obras da UC Digitalis se encontram protegidas pelo Código do Direito de Autor e Direitos Conexos e demais legislação aplicável, toda a cópia, parcial ou total, deste documento, nos casos em que é legalmente admitida, deverá conter ou fazer-se acompanhar por este aviso.

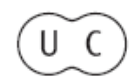




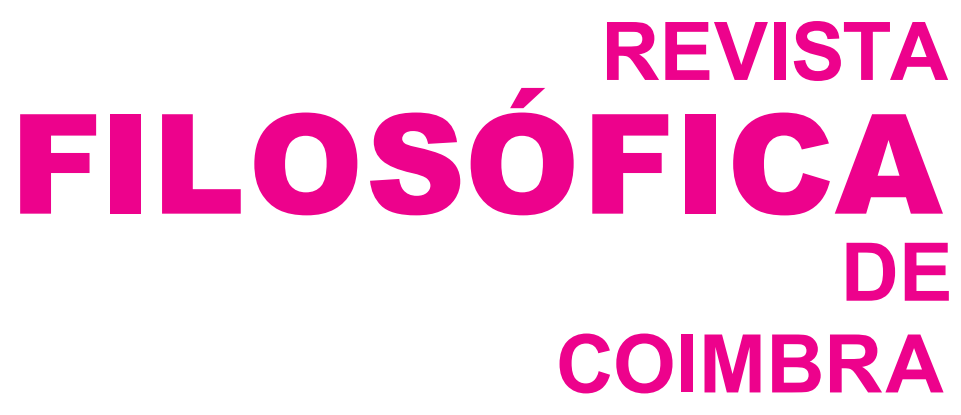

vol. 24 - número 48 - outubro 2015

vol. 24 - número 48 - outubro 2015

Fundação Eng. António de Almeida

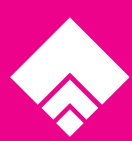




\section{LEITURA FENOMENOLÓGICA DO TEXTO MEDIEVAL: A FAUNA DE UM PAÍS LONGÍNQUO OU UM PENSAMENTO UNIVERSALMENTE SINGULAR?}

DIOGO MORAIS BARBOSA*

Resumo: Para alguns leitores, o texto de filosofia medieval é visto como o império das bizantinices. São muitos os leitores para os quais aquele tipo de textos não tem peso na (ou, em todo o caso, não interessa para a) vida normal e corrente do homem contemporâneo. Isto é tanto mais assim na medida em que os próprios medievalistas insistem em seguir uma determinada linha interpretativa, pautada por notas bem concretas e por contornos bem delimitados. De facto, os estudiosos tendem a lançar-se no empreendimento de filosofia medieval como quem explora «a fauna de um país longínquo», para adotar a expressão de Merleau-Ponty. Este artigo desenvolve-se em dois momentos: no primeiro, é apresentado o modelo da fauna; e, no segundo, procura-se mostrar que a leitura fenomenológica do texto medieval assenta num outro modelo, que pode ser designado como «pensamento universalmente singular». Ao longo do artigo, toma-se como exemplo o corpus augustinianum.

Palavras-chave: texto de filosofia medieval, leitura fenomenológica, fauna de um país longínquo, pensamento universalmente singular, Agostinho.

\footnotetext{
Abstract: For some readers, the spirit of medieval philosophy most often falls within the scope of Byzantinology. Conceptually, since medievalists insist on following a particular interpretative line of reasoning, which is marked by well-defined and delimited thoughts, this perspective advocates that such texts are of limited value for day-to-day life in the modern world. In fact, while using a Merleau-Ponty's terminology, scholars tend to launch themselves in the venture of medieval philosophy as if they intended to «explore fauna of a distant country». This article is struc-

* Membro colaborador da Unidade Linguagem, Interpretação e Filosofia (LIF). Doutorando de Filosofia pela Universidade de Coimbra, e bolseiro da Fundação para a Ciência e Tecnologia; email: diogobarb@gmail.com.
} 
tured in two distinct sections: in the first section we deal with the model underlying the notion of fauna and then, in the second section, we intend to demonstrate that the phenomenological approach to medieval text is based on another template; one that can be designated as «universally singular judgment». The corpus augustinianum is used throughout the article as an example.

Key-words: medieval philosophy text, phenomenological thinking, fauna of a distant country, universally singular judgment, Augustine.

Para alguns leitores, o texto de filosofia medieval é visto como o império das bizantinices. São muitos os leitores para os quais aquele tipo de textos não tem peso na (ou, em todo o caso, não interessa para a) vida normal e corrente do homem contemporâneo. Isto é tanto mais assim na medida em que os próprios medievalistas insistem em seguir uma determinada linha interpretativa, pautada por notas bem concretas e por contornos bem delimitados. De facto, os estudiosos tendem a lançar-se no empreendimento de filosofia medieval como quem explora «a fauna de um país longínquo», para adotar a expressão de Merleau-Ponty ${ }^{1}$. Este modelo vai buscar as suas raízes a um solo profundo, e fundamenta-se numa atitude simultaneamente esconsa e operante.

Tudo brota do ato, aparentemente inocente, de pegar num livro de filosofia medieval como as Confissões. A pergunta é esta: ao abrir aquela obra, o investigador tem dúvidas de fundo quanto à possibilidade de aceder ao ponto de vista de Agostinho? Em condições normais - primariamente e o mais das vezes -, a resposta é um «não» contundente e rotundo. Se houvesse alguma dúvida significativa sobre tal possibilidade, era muito provável que o livro ficasse na prateleira, pois o propósito da sua leitura estaria alegadamente votado ao fracasso: para quê ler um livro de Agostinho, se o seu autor é inacessível? Para nada, ao que parece. Esta resposta e esta atitude de fundo refletem um conjunto de suposições esconsas - mas nem por isso menos operantes - acerca do que está em causa na leitura de um texto de filosofia medieval. Concretizando com o corpus augustinianum, pode-se dizer que existe um aparato de teses ocultas sobre o que significa ler, nos tempos que correm, a obra de um filósofo medieval como Agostinho.

A primeira nota do modelo da fauna a relevar é a sua pretensão de objetividade. Costuma-se dizer, nas conversas de praça pública, que o investigador «tem de ser objetivo» (ou que, pelo menos, deve tentar sê-lo). Segundo a

1 Leia-se Merleau-Ponty, Phénoménologie de la Perception (Paris: Gallimard, 1945), 240: «O filósofo descreve as sensações e o seu substrato como se descreve a fauna de um país longínquo». 
perspetiva habitual, a indagação filosófica será tanto mais séria quanto mais anular a subjetividade. Num processo anónimo - isto é, de subtração do sujeito -, importará atender ao objeto ele mesmo, enquanto tal. A pretensão de objetividade embarca, justamente, na ideia de que o medievalista explora a fauna de um país que não é o seu. Trata-se de alguém que, tal qual um turista, visita uma região que não lhe diz diretamente respeito, um sítio que está longe de ser a sua casa e que, por isso, pode ser contemplado com distanciamento, de forma anónima - com objetividade, portanto. A ser assim, o medievalista poderá viver o empreendimento filosófico como um «espetador de bancada» - isto é, como alguém que contempla, a partir de cima, aquilo que lhe é dado a assistir. De acordo com este modelo, os textos medievais saem do punho de autores ao mesmo tempo alheios e acessíveis. As Confissões, por exemplo, são da autoria de Agostinho e de mais ninguém; mas, ao arrepio deste facto, a obra está aí, à disposição de quem quiser lê-la - de sorte que, ao que tudo indica, os demais pontos de vista poderão aproximar-se dela ao modo de um explorador que investiga a fauna de um país longínquo.

O exposto chama a si mais duas notas do modelo da fauna, que se implicam reciprocamente. Por uma parte, a tese de que o ponto de vista próprio é adequado para compreender aquelas que são designadas como «perspetivas alheias». Por outra parte, a ideia de que essas mesmas perspetivas alheias são transparentes para o ponto de vista próprio. A tese da adequação é de tal modo importante para o modelo da fauna que, como se viu, a impossibilidade de aceder ao ponto de vista de Agostinho convida a deitar por terra a leitura mesma das Confissões. Tal não significa que se ignorem os esforços que a compreensão daquela obra pode exigir. O medievalista está prevenido para o facto de poder encontrar resistências na leitura dos textos. Contudo, os motivos para tais esforços e resistências são frequentemente identificados com fatores extrínsecos à perspetiva do investigador enquanto tal. A raiz das dificuldades é muitas vezes identificada com problemas inerentes à compreensão da língua latina, às deficiências da tradução adotada, ou até mesmo ao estilo dos autores medievais, nomeadamente de Agostinho. Em condições normais (leia-se: postas de lado estas e outras resistências de caráter extrínseco), o ponto de vista próprio conseguirá aceder às perspetivas alheias. Por inerência, e como «a outra face da mesma moeda» (passe a expressão), não é raro experimentar-se a perspetiva de outrem como sendo transparente. Com maior ou menor esforço, com mais ou menos dificuldades, a perspetiva do medievalista julga conseguir abarcar Agostinho, por exemplo.

Assumidas as notas da objetividade, da adequação e da transparência, surge, como consequência lógica, um quarto elemento a inspecionar. Com efeito, aquelas teses implicam que o medievalista vive o seu ponto de vista na pressuposição de que é superior àquela que é designada como «a perspetiva dos filósofos medievais». Sem dúvida que ele não diz ter uma mente mais 
aguda do que o espírito de Agostinho. Aliás, ao ser-lhe perguntado se assim é, costuma até mesmo excluir a hipótese sem hesitar. No entanto, nem sempre o que se afirma vai a par daquilo que se vive. A verdade é que o ponto de vista próprio se experimenta, constantemente - de modo obscuro e atemático - como um ponto de vista superior. Julga, efetivamente, não estar absorto na ebulição do texto filosófico - e esta distância sugere uma superioridade. Por exemplo: ao ler a tese augustiniana segundo a qual o coração humano está inquieto $^{2}$, o intérprete experimenta-se muitas vezes como alguém de fora ou seja, como alguém impassível, neutro, capaz de considerar, à distância, aquilo que the é relatado. Tal qual um «espetador de bancada», ele está longe de «entrar em jogo» - quer dizer, não é um dos homens que está inquieto. É como se o facto relatado fosse um objeto de estudo que não tivesse implicações na sua vida quotidiana. O seu ponto de vista parece não entrar em cena. Contempla tudo, de modo especulativo.

$\mathrm{E}$ aqui toca-se um ponto decisivo, que pode ser aclarado mediante a análise do termo que acabou ser adotado: «especulativo». A palavra remete para a noção de $\pi \varepsilon \rho \iota \omega \pi \eta ́$ ou specula - isto é, para a ideia de um lugar de observação mais elevado e que corresponde a um espetáculo muito mais abrangente ${ }^{3}$. Ao ponto de vista especulativo do investigador opõem-se as perspetivas de filósofos medievais como Agostinho, perspetivas essas que estão submersas no acontecimento, voltadas para baixo - de tal forma que dispõem de um ângulo de apreensão mais restrito. Noutros termos, o ponto de vista próprio tende a experimentar-se como objetivo e adequado justamente porque se julga menos angulado do que os pontos de vista que se dizem «alheios», nomeadamente os chamados «pontos de vista dos filósofos medievais». Encontra-se como que posto num lugar superior, de tal modo que é capaz de aceder à perspetiva de Agostinho como uma perspetiva transparente ao seu ponto de vista.

Esta experiência é tal que o ponto de vista próprio se vive como um visor que tudo abarca ou pode abarcar. Não se revela necessário recorrer a muitas teorias para dar a ver este pressuposto. Basta chamar a experiência interna à colação: num dia banal de um ano comum, um qualquer estudante de filosofia medieval pode começar a manhã com a leitura de Agostinho, continuá-la ao compasso de Boaventura, passar a tarde na companhia de Duns Escoto e terminar o dia ao ritmo de Tomás de Aquino... Nestes atos de pegar alternadamente em textos de filosofia medieval, e em textos de filosofia com apro-

2 Leia-se Agostinho, Conf. I, I, 1, CSEL, XXXIII, 1: «O nosso coração está inquieto» («inquietum est cor nostrum»).

3 Cfr. Diogo Morais Barbosa, «Natura Semper in se Curva» - A Vinculação a Si e a Possibilidade de Desvinculação Segundo Duns Escoto (Porto: Fundação Eng. ${ }^{\circ}$ António de Almeida, 2012), 31, nota 35. 
ximações tão distintas e distantes entre si, esconde-se a tese de que o ponto de vista próprio é capaz de abarcar várias perspetivas - e de abarcá-las todas à uma. Mais e melhor: esconde-se a tese de que é capaz não só de abarcá-las mas também de ajuizar qual reflete uma mundividência «mais acertada». É por isso que se diz, nas discussões filosóficas habituais, que «Agostinho tem razão quando afirma que o coração humano está inquieto», ou que «Boaventura veio chamar as coisas pelos nomes», ou que «Duns Escoto tem frases desajustadas, ao passo que Tomás de Aquino acerta quase sempre». Todas estas frases refletem a ideia de que o ponto de vista próprio é superior e, à distância, consegue ver mais e ajuizar melhor aquelas que são olhadas como perspetivas «alheias». Numa palavra: refletem a ideia de que se trata de um ponto de vista que tudo abarca ou pode abarcar.

Veja-se como o âmbito da análise está a ser alargado. Num primeiro momento, considerou-se um único ponto de vista «alheio». Agora, está-se a ver que o acesso pretende ser objetivo, adequado, superior e transparente não só em relação a Agostinho, mas também - e ao mesmo tempo - em relação a Boaventura, Duns Escoto e Tomás de Aquino. Na verdade, a tese de fundo mantém-se inalterada até mesmo ao fazer-se um alargamento indefinido, ou ad infinitum. E a tese de fundo é esta: existe um ponto de vista que se vive como explorador de um país que não é o seu - o país dos medievais; o império das bizantinices.

Toca-se, assim, mais uma nota caraterística do modelo da fauna, a saber: a pressuposição de que, no momento em que pega num livro de filosofia medieval, o ponto de vista do intérprete está indeterminado. A tese mais não é do que a consequência lógica do que tem vindo a ser visto. Assim como um turista «vai ver as vistas» num sítio que não lhe diz diretamente respeito, assim também o medievalista se experimenta - o mais das vezes e primariamente - como alguém cujo ponto de vista está por preencher, em branco, por determinar. Tudo se passa de acordo com o fenómeno designado por Heidegger como «Das Man»: o medievalista tende a ser como toda a gente e ninguém, a deixar-se levar pela curiosidade (Neugier) do que os outros vão dizendo (Gerede), a lançar-se na leitura daquilo para que lhe dá, lendo muito de tudo e assimilando pouco também de tudo, numa espécie de ambiguidade (Zweideutigkeit) própria de um qualquer animal híbrido ou camaleónico ${ }^{4}$. O seu modo de ver é alegadamente anónimo, podendo ser preenchido pelas perspetivas de outrem. Sem mais nem menos (assim mesmo), explora a fauna de um país longínquo: o país de Agostinho, de Boaventura, de Duns Escoto, de Tomás de Aquino, ou de quem quer que esteja na prateleira, à disposição - pronto para ser lido.

${ }^{4}$ Cfr. M. Heidegger, Ser e Tempo (Petrópolis: Vozes, 1988), trad. Marcia Sá Cavalcante Schuback, 226-236. 
Sucede que esse não é, de todo em todo, o mundo próprio, pessoal, feito de carne e de osso. Erguem-se assim países paralelos à fauna da existência contemporânea, ao jeito de uma esquizofrenia de vida e de costumes. A cada filósofo medieval corresponde um país suscetível de exploração, de visita, de contemplação. Mas a mulher e os filhos do medievalista estão na pátria. É aí que a sua vida tem livre curso. É nesse país que ele se diverte, come, dorme, etc. Depois, em horário de expediente, como que interrompe o curso da sua existência e viaja para o estrangeiro, em negócios alheios.

A descrição pascaliana do autómato e da inspeção do espírito ${ }^{5}$ tem que ver com esta suposição. Por um lado, existe um conjunto de determinações a vigorar automaticamente no ponto de vista: são as determinações existenciais, correspondentes ao curso da vida. Por outro lado, existe um conjunto de determinações que se ativam mediante um esforço do espírito: são as determinações teóricas, próprias de filósofos medievais como Agostinho. Ao contrário do que se passa na vertente automática, as determinações do segundo tipo influem no ponto de vista do medievalista apenas durante o tempo que ele lhes dedica, e tão-somente na medida em ele se lhes entrega. Basta o investigador passar a inspecionar outras determinações para estas serem votadas ao esquecimento ${ }^{6}$. A filosofia é, portanto, vista como uma realidade abstrata, à parte, distante da vida quotidiana de quem tem mulher e filhos, de quem quer divertir-se e tem de comer.

A imagem de Merleau-Ponty está a ser elucidada com algum detalhe. As teses obscuras foram trazidas à luz do dia, e o texto de filosofia medieval apareceu como uma fauna paralela, incógnita, desconhecida, alheia à pátria do medievalista. Esta tem uma fauna própria, e é nela que se efetiva o curso da existência. É aí que estão a mulher e os filhos com quem se vive, os passatempos que divertem, o alimento que se come e o leito onde se dorme. Depois, existem outros países, distantes, remotos, alheios às circunstâncias normais e correntes de uma existência mais ou menos banal. Por exemplo: na sua vida, o medievalista convive com corações tranquilos e descansados; é no horário de trabalho (só aí, não mais do que aí) que ele topa com corações inquietos - os quais não passam de objetos de estudo, encerrados nas caves recônditas de um qualquer laboratório filosófico.

Este modelo formal é passível de várias desformalizações. Cabe destacar duas, por serem particularmente frequentes na leitura dos textos medievais. A primeira funda-se na tese de que a inteligibilidade do texto filosófico reside na psicologia ou, mais propriamente, na chamada «psicologia do autor»».

${ }^{5}$ Cfr. Pascal, Pensées, texto fixado por Louis Lafuma (Paris: Seuil, 1978), 565.

6 Não se dará resposta à questão de saber se existem determinações do plano espiritual suscetíveis de passar para o plano automático (ou vice-versa). Tal problema não se enquadra no âmbito do presente artigo. A este propósito, cfr. Pascal, Pensées, 565. 
Segundo esta abordagem, a interpretação deverá centrar-se no estudo do que terá levado certo filósofo medieval a firmar determinadas teses. Tal desformalização é particularmente comum quando se trata de interpretar os textos de um filósofo como Agostinho. A partir dela, alega-se, por exemplo, que «Agostinho descreveu o coração humano como sendo inquieto porque vivia angustiado», ou que «passou por muitas coisas más na vida e o intérprete deve ter isso em conta», ou ainda (e este caso é dos mais frequentes) que «a visão de Agostinho começa por ser otimista mas vai-se tornando cada vez mais pessimista».

Sem dúvida que, habitualmente, a atitude psicológica não é assumida de modo tão manifesto. No entanto, de uma forma mais ou menos caricatural, o que está em jogo é a ideia de que o medievalista deve adquirir qualquer coisa como um «olhar psicológico»: tem de contemplar, à distância, para ativar a possibilidade de avaliar os filósofos medievais «com mais objetividade» do que eles mesmos. Segundo esta desformalização, para captar a essência da obra augustiniana, por exemplo, o sujeito tem de compreender o que nela é objetivo, por um lado, e, por outro lado, o que é resultado do pessimismo crescente que (alegadamente) se verifica na mente do seu autor (como se o otimismo fosse o paradigma da objetividade).

A segunda desformalização que convém destacar é aquela que radica a chave de inteligibilidade na história. O recurso à Crítica da Razão Pura pode servir de porta de entrada para entendê-la. Naquela obra, Kant indica que todo o conhecimento é, subjetivamente, ou histórico ou racional. E, quando se trata de explicar o que está em causa no primeiro tipo de saber, escreve o seguinte:

«Qualquer conhecimento dado originariamente, seja qual for a sua origem, é histórico naquele que o possui, quando esse não sabe nada mais do que aquilo que lhe é dado de fora [...]. Por isso, aquele que aprendeu especialmente um sistema de filosofia, por exemplo o de Wolff, mesmo que tivesse na cabeça todos os princípios, explicações e demonstrações, assim como a divisão de toda a doutrina e pudesse, de certa maneira, contar todas as partes desse sistema pelos dedos, não tem senão um conhecimento histórico completo da filosofia wolffiana. Sabe e ajuíza apenas segundo o que lhe foi dado. Contestais-lhe uma definição e ele não sabe onde buscar outra. Formou-se segundo uma razão alheia, mas a faculdade de imitar não é a faculdade de invenção, isto é, o conhecimento não resultou nele da razão e embora seja, sem dúvida, objetivamente, um conhecimento racional, é contudo subjetivamente histórico. Compreendeu bem e reteve bem, isto é, aprendeu bem e é assim a máscara de um homem vivo» ${ }^{7}$.

${ }^{7}$ Kant (Lisboa: Fundação Calouste Gulbenkian, 6. ${ }^{\mathrm{a}}$ edição, 2008), trad. Manuela P. dos Santos e Alexandre F. Morujão, 659-660. 
Mais do que acentuar o tom polémico do excerto, importa ir na pista do argumento decisivo. Kant afirma que todo o conhecimento histórico é dado, ou seja, vem de fora; trata-se de um conhecimento que se alimenta exclusivamente dos dados - é ex datis. O sentido desta tese é captado mediante a reinvocação do modelo formal da fauna. Aventou-se a existência de um ponto de vista que abarque objetiva e adequadamente outras perspetivas - as quais lhe são, por sua vez, transparentes e inferiores. Ora, isto é justamente o que parece estar envolvido na tese de que o conhecimento histórico, ao ater-se aos dados, se funda numa razão alheia. Quer dizer, o historiador das ideias pode ajuizar muito bem todas as perspetivas ditas «alheias» (ouve-se ao fundo a tese de que o ponto de vista próprio tudo abarca ou pode abarcar...), mas nem por isso conseguirá passar da faculdade de imitação para a faculdade de invenção. Bem vistas as coisas, nem se trata de conseguir ou não conseguir fazê-lo: trata-se antes de não ser esse o seu propósito. Como historiador das ideias, o medievalista que se rege pelo modelo da fauna pretende adquirir um conhecimento histórico, e não um conhecimento racional. Este é o motivo pelo qual não se segue o tom polémico adotado por Kant. O historiador das ideias - um medievalista, por exemplo - não é a máscara de um homem vivo: quem usa uma máscara quer esconder aquilo que é e aparentar outra coisa; mas o historiador das ideias não quer nem uma coisa nem a outra. Simplesmente é o que é. Nem mais, nem menos. Ora, para um medievalista deste género, a inteligibilidade de um texto como as Confissões expressa-se em frases como a que diz que, «para se perceber Agostinho, temos antes de tudo de enquadrá-lo no contexto da queda do império». Justamente porque (repita-se) o enquadramento histórico é tomado como a chave de inteligibilidade.

São muitas as leituras medievais em que a psicologia e a história não vigoram no seu estado puro. É raro, aliás, encontrar-se qualquer coisa como um «puro psicólogo» ou como um «puro historiador» medieval. Por outro lado, o cruzamento da psicologia e da história é até mesmo a expressão mais comum do modelo da fauna. E isto é particularmente flagrante no estudo do corpus augustinianum. A forma mista de acercamento é adotada por augustinianos de peso, dentre os quais importa destacar Kurt Flasch. E importa destacá-lo porque este comentador, além de desformalizar o modelo que foi visto, opõe-se frontalmente ao que será proposto mais adiante.

Comece-se pela desformalização. Logo na primeira linha da sua obra introdutória ao pensamento augustiniano, Flasch afirma ser difícil (mas não impossível, note-se bem) produzir uma exposição abrangente de Agostinho. $\mathrm{E}$, quando se trata de indicar as razões para a dificuldade, cinge-se àqueles que já foram descritos como «motivos extrínsecos ao ponto de vista próprio». Com efeito, fala da imensidão da obra de Agostinho, do caráter pouco comum das suas teses, da falta de acordo entre os intérpretes na delimitação dos 
objetos próprios de cada ciência, e da dificuldade que a época contemporânea tem em identificar as raízes históricas do pensamento augustiniano ${ }^{8}$. Todos estes motivos têm em comum a circunstância de caírem no âmbito das teses próprias do modelo da fauna. Em primeiro lugar, o intérprete experimenta-se como alguém que é capaz de aceder ao ponto de vista augustiniano de modo adequado e transparente (mesmo que tal solicite algum esforço). Esta não é uma interpretação ousada, pois é o próprio Flasch a expressá-la, de modo taxativo e sem margem para qualquer dúvida:

«É possível, desde há aproximadamente um século, compreender o pensamento de Agostinho na dimensão histórica que lhe é própria; por isso, podemos acompanhar a evolução interior de Agostinho, conhecer os acontecimentos relativos aos seus adversários e aos seus defensores e determinar as consequências históricas do seu pensamento. $\mathrm{O}$ estado das fontes é favorável à reconstrução que, habitualmente, Agostinho atribuiu a um determinado motivo na escala dos valores. A pesquisa histórica é capaz de exprimir a pertença a um mundo passado e a presença de uma personalidade muito singular» ${ }^{9}$.

Em segundo lugar, este mesmo excerto acaba por remeter para a tese da superioridade da mundividência própria. Tudo ocorre na pressuposição de ser possível o que, logo a seguir a esta passagem, Flasch chama «distância histórica» ${ }^{10}$. Um pouco adiante, o mesmo Flasch especifica que o seu modelo interpretativo convida, por um lado, a expor a evolução do pensamento augustiniano sem modernizá-lo e, por outro lado, a fazer diligências para uma aquisição de verdade ${ }^{11}$. Esta última sugestão remete, em terceiro lugar, para a ideia de que a perspetiva do medievalista é uma perspetiva «em aberto»,

8 Leia-se Kurt Flasch, Agostino d'Ippona - Introduzione all'Opera Filosofica (Bolonha, Il Molino, 2002), trad. Claudio Tugnoli, 7: «Uma exposição global do pensamento de Agostinho é uma tarefa difícil. Isto tem razões concretas: a dificuldade de dominar a sua obra imensa, o carácter pouco comum das suas ideias de fundo e a distribuição de competências próprias aos historiadores, aos filólogos, aos filósofos e aos teólogos. Por outro lado, a nossa época não é capaz de esclarecer as próprias bases históricas se não tenta delinear o pensamento e a obra de Agostinho, bem como a sua forte influência, no interior de um novo quadro». Todas as traduções portuguesas são pessoais, pese embora feitas com base na edição italiana.

${ }^{9}$ Cfr. Kurt Flasch, Agostino d'Ippona - Introduzione all'Opera Filosofica, 12. Itálico acrescentado.

10 Para uma crítica à noção de distância histórica, bem como aos estudos histórico-tipográficos, cfr. M. Heidegger, The Phenomenology of Religious Life (Bloomington e Indianopolis: Indiana University Press, 2004), trad. Matthias Fritsch e Jennifer G. Ferencei principalmente as páginas $115-2$, correspondentes à introdução ao curso de verão sobre Agostinho e o neoplatonismo.

11 Cfr. Kurt Flasch, Agostino d'Ippona - Introduzione all'Opera Filosofica, 13. 
justamente porque, ao acercar-se da mundividência augustiniana, se experimenta como indeterminada. Neste sentido, vive-se como uma perspetiva capaz de abarcar todas as propostas medievais existentes (mesmo que estas sejam - e muitas vezes são-no - mutuamente exclusivas) e ajuizar acerca do seu valor de verdade.

Falta atender à pretensão de objetividade. A este respeito, Flasch não é tão taxativo. Na verdade, a leitura puramente objetiva de Agostinho consistiria num deslize da filosofia para a ciência, e os textos de Flasch parecem ter isso em conta. Também Unamuno, que vê no modelo biográfico a epifania do autor em carne e osso ${ }^{12}$, se dizia incapaz de produzir juízos objetivos porque era, não um objeto, mas sim um sujeito. Apesar deste facto, a proposta de Flasch assenta na convicção de que se pede demasiado à capacidade subjetiva de aquisição se se pretende passar ao lado da diferença de idade históri$\mathrm{ca}^{13}$. Isto significa que toda a subjetividade possível deve estar subordinada a uma alegada objetividade histórica. E é justamente este argumento que leva Flasch a opor-se ao método que vai ser proposto. Para ele, convém ter muito presente que Agostinho pertence a uma época de transição, e considerar que este facto histórico influencia sobremaneira a sua produção filosófica:

«Uma vez que Agostinho pertence a um mundo histórico que já não é o nosso, [uma introdução ao seu pensamento] deve procurar compreender Agostinho no seu contexto histórico» ${ }^{14}$.

\section{E outra vez:}

«Atualmente, um livro sobre Agostinho já não pode não ter uma base histórica» ${ }^{15}$.

Ora, posto que o mundo do homem-Agostinho não é o contemporâneo, a separação entre história e filosofia é vista por Flasch nada mais e nada menos do que como uma «distinção pedante» ${ }^{16}$.

Mas não é só de história que se trata. A obra daquele medievalista também conta com a psicologia, na sua forma de psicologia do autor. Com efeito, a convicção de que o projeto filosófico e a pesquisa histórica constituem uma unidade leva-o a vincar a necessidade de atender ao que Agostinho realmente quis dizer, no seu período de vida bem concreto e historicamente de-

12 Unamuno, Del Sentimento Trágico de la Vida - En los Hombres y en los Pueblos (Madrid: Epasa-Calpe, S. A., 4. ${ }^{\text {a }}$ edição, 1985), 25-39.

13 Cfr. Kurt Flasch, Agostino d'Ippona - Introduzione all'Opera Filosofica, 14.

14 Kurt Flasch, Agostino d'Ippona - Introduzione all'Opera Filosofica, 11. Itálico acrescentado.

15 Kurt Flasch, Agostino d'Ippona - Introduzione all'Opera Filosofica, 12.

16 Kurt Flasch, Agostino d'Ippona - Introduzione all'Opera Filosofica, 9. 
limitado. Flasch considera que, nos anos da sua existência, Agostinho nunca é um «puro teórico». Pelo contrário: respondeu com o seu pensamento às experiências vividas naquele mundo que se encaminhava rapidamente para a dissolução ${ }^{17}$. A partir desta circunstância, parece ser fundamental produzir um acompanhamento da evolução interior de Agostinho. Ao que tudo indica, este acompanhamento mostrará que o seu interior se foi deixando tomar cada vez mais pelo pessimismo - algo que, sempre segundo Flasch, não deve ser desconsiderado pelo intérprete da sua obra filosófica.

O caminho percorrido, na companhia de Kurt Flasch, permite responder agora a uma objeção ao que foi visto sobre as aproximações psicológica e histórica. Poder-se-ia sustentar que estes dois modos de entender o texto medieval não são desformalizações do modelo da fauna. Existe, de facto, uma tendência a pensar que a psicologia e a história pertencem à fauna própria, isto é, são ciências que habitam a pátria do medievalista. Mas, se não se está em erro, quer as categorias psicológicas quer as históricas radicam a chave de inteligibilidade num país onde o medievalista não está realmente. É o próprio Flasch a dizê-lo, de um modo que não deixa margem para dúvidas, precisamente na obra que tem vindo a ser citada: «o mundo de Agostinho já não é nosso» ${ }^{18}$. De facto, ao ler a obra augustiniana, o medievalista não está no seu mundo porque, por uma parte, a mente de Agostinho não corresponde à sua perspetiva (justamente: corresponde à perspetiva do homem-Agostinho); e, por outra, o mundo da queda do império não é o mundo contemporâneo (justamente: é o mundo da queda do império). Por conseguinte, as categorias psicológicas e históricas afastam mesmo o texto de filosofia medieval (nomeadamente o corpus augustinianum) da situação atual em que a vida do investigador se desenrola. Não abarcam as categorias da existência própria. São categorias de uma fauna cujo país está distante. Numa palavra: «o mundo de Agostinho já não é o nosso» ${ }^{19}$.

17 Cfr. Kurt Flasch, Agostino d'Ippona - Introduzione all'Opera Filosofica, 12.

18 Kurt Flasch, Agostino d'Ippona - Introduzione all'Opera Filosofica, 11.

19 A propósito da aplicação concreta deste tipo de leitura ao conceito augustiniano de imagem, leia-se Saturnino Turienzo, «Regio Media Salutis» - Imagen del Hombre y su Puesto en la Creación: San Agustín, Universidad Pontificia de Salamanca (Salamanca: Biblioteca de la Caja de Ahorros e M. P. de Salamanca, 1988), 160-161: «O caraterístico do período anterior a 395 (de um modo particular, o de recém-convertido) é o recurso à doutrina da imagem como "lugar-comum" da tradição religiosa - quer dizer, sem problematizar o significado da expressão. No segundo período, desde 396/397, acentua os efeitos do pecado do primeiro homem e fala da "perda" da imagem (embora já haja expressões semelhantes em escritos anteriores). Num caso, partilha o otimismo dos filósofos, pelo menos naquilo em que os considera compatíveis com a verdade cristã. No outro, pelo contrário, coloca a tónica nos aspetos obscuros da vida, ao ver o homem pelo seu lado pessimista». Refira-se, no entanto, que esta aparição dos registos histórico e psicológico 
Posto isto, estão criadas as condições para apresentar o modelo do pensamento universalmente singular. Ao mesmo tempo, o modelo da fauna longínqua será definitivamente excluído do acercamento fenomenológico ao texto de filosofia medieval.

Afirmar que o modelo da fauna se afasta do acercamento fenomenológico do texto de filosofia medieval significa, em primeiro lugar, que o fenomenólogo não pretende estudar o que é que os filósofos medievais pensaram ou quiseram afirmar. $\mathrm{O}$ mesmo é dizer que não pretende levar a cabo uma investigação nos moldes da psicologia. Este é um ponto que tem de ficar absolutamente claro. Para tal, recorra-se novamente às leituras que se costumam fazer de Agostinho. Maria Leonor Xavier afirma que o autor não é um elemento restritivo, mas sim um meio de relacionamento com a tradição. $\mathrm{Na}$ sua dissertação de mestrado sobre um problema do corpus augustinianum, escreve que «o texto deverá [...] servir de introdução ao autor, desempenhando este, em relação àquele, uma função essencialmente contextual» ${ }^{20}$. Neste artigo, assume-se o risco de defender o oposto: se se está a ver bem, o que possui uma função essencialmente contextual é, não o texto, mas sim o autor. E uma função contextual que é irrelevante do ponto de vista filosófico. Isto porque, para o fenomenólogo, o autor enquanto autor desaparece por completo. Em vez de relegar os fenómenos enquanto tais para segundo plano, ele silencia absolutamente o autor enquanto autor e deixa o texto falar, por si, dos fenómenos comuns a toda e qualquer existência humana.

Neste sentido, a eventual impossibilidade de aceder às perspetivas dos filósofos medievais não afeta, em nada, a leitura fenomenológica. Não importa nada se a perspetiva própria é ou não é objetiva, adequada, superior e/ou omniabarcante, nem se as demais mundividências lhe são ou não são transparentes e inferiores. É bem provável que as alegadas perspetivas «alheias» não passem disso mesmo: perspetivas alheias apenas de dicto, e jamais de re. A possibilidade mesma de existirem perspetivas alheias enquanto tais (isto é, enquanto alheias) não é nada linear. Sucede que, para a leitura fenomenológica, esta circunstância é pouco ou nada relevante. Por quê? Porque o âmbito é absolutamente outro.

Como se viu, Kurt Flasch é um dos (muitos) defensores da possibilidade de acompanhar o interior dos medievais desde a sua génese e no seu contexto histórico. Uma tal afirmação pode ser vista como temerária e, ao limite, como infundada. É possível (provável?) que o facto de Agostinho, por exemplo, não estar vivo impossibilite, desde logo, um conhecimento certo

na obra de Saturnino é muito fugaz. Na verdade, são muito mais os pontos que aproximam o seu pensamento do método a seguir do que aqueles que o separam.

20 Maria Leonor Xavier, Santo Agostinho - Pensar, Conhecer, Ensinar em «De Magistro» (Lisboa: dissertação de mestrado, apresentada à Universidade de Lisboa, 1985), V. 
daquilo que ele pensou no seu interior e quis dizer aos seus interlocutores. É bem provável que aquilo que Flasch designa como «as fontes» não baste para se poder falar de uma perspetiva alheia. No entanto (repita-se), esta possibilidade não afeta em nada a leitura fenomenológica dos textos medievais. De facto, o modelo seguido não tem nada que ver com os filósofos - por exemplo, não tem nada que ver com a perspetiva de um homem que exerceu o episcopado em Hipona.

Em segundo lugar, afirmar que o modelo da fauna se afasta do acercamento fenomenológico equivale a afirmar que não se vai ao texto medieval para analisar nem a sua génese nem a sua história. O modelo fenomenológico não se pauta pelas categorias históricas, que atribuem aos textos medievais o caráter de obras mais ou menos arqueológicas ${ }^{21}$. Longe de se atribuir ou reconhecer à história o valor de verdade em filosofia medieval, sugere-se o modelo do pensamento universalmente singular ${ }^{22}$. É provável, por isso, que a leitura fenomenológica não tenha muito ou até mesmo nada que ver nem com a história, por exemplo, do homem-Agostinho nem com qualquer coisa como o seu «mundo interior». Todavia, é certo que tem que ver, em tudo, com a vida do homem contemporâneo que lê aquele corpus. A relação que o fenomenólogo pretende estabelecer é, não com Agostinho, mas sim com os fenómenos que, a partir de um corpus como o augustinianum, são experimentados pelo medievalista na sua existência ${ }^{23}$. Quer dizer, ao pegar

21 A propósito da pretensão de uma leitura histórico-arqueológica, leia-se o seguinte exemplo, que se pode considerar extremo (mas não raro): «A nossa investigação terá caraterísticas semelhantes às dos arqueólogos, os quais, cuidadosamente, analisam cada etapa geológica, cada etapa do pensamento, para encontrar aí ruínas significativas que nos deem a chave da história, neste caso da reflexão augustiniana» (Maria del Carmen Dolby, El Hombre Es Imagen de Dios - Visión Antropológica de San Agustín (Pamplona: Eunsa, 2. ${ }^{\text {a }}$ edição, 2002), 20.

22 Cfr. Mário Santiago de Carvalho, A Síntese Frágil - Uma Introdução à Filosofia (Da Patrística aos Conimbricenses) (Lisboa: Colibri, 2002), 19.

23 Algo de semelhante é dito por Mário Jorge de Carvalho, «Problemas de Desconfinamento de Perspectiva - Pensar por Si, o Pensamento de Outrem e Alguns Preconceitos Sobre a Filosofia Actual e o Passado da Filosofia», in Cassiano Reimão (ed.), Os Longos Caminhos do Ser - Homenagem a Manuel Barbosa da Costa Freitas (Lisboa: Universidade Católica Editora, 2003), 117-38, principalmente 121: «Para efeitos de indagações não históricas, mas sim filosóficas, os filosofemas não se distinguem pelas épocas de que provêm, mas pelo modo como dão que pensar, suscitam reflexão, abrem pistas, indiciam possibilidades pertinentes, numa palavra: como se prestam ou não ao desempenho de catalisadores da análise e do debate filosóficos e contribuem ou não para compreender mais incisivamente o que se passa connosco, aquilo a que assistimos, a situação em que nos encontramos». Já antes, na página 119, o autor havia centrado a sua crítica na leitura do texto filosófico em registo histórico: «Convém sublinhar que se partilha inteiramente a convicção de que a conversão do trabalho filosófico em trabalho de história da filosofia 
num livro, o fenomenólogo não se propõe a nada menos do que a vislumbrar pessoalmente os fenómenos da existência humana enquanto tais. Mas não se propõe, tão-pouco, a nada mais do que isso: a um vislumbre, «somente» a partir do que é próprio, numa relação com o texto enquanto texto.

A fenomenologia adota este modelo na convicção de que os textos de filosofia medieval são biografias. Melhor ainda: são autobiografias. É incontestável que os fenómenos são detetados por espíritos singulares e trabalhados com penas de um período delimitado historicamente. Não se nega, portanto, que estejam circunstancialmente moldados por determinadas categorias históricas. Mas defende-se que essas palavras, proferidas segundo determinadas categorias, podem fazer-se carne em cada homem de cada época. E, se não o podem, são existencialmente insignificantes, no sentido forte da expressão: não interessam, não pesam no ponto de vista próprio - são do império da bizantinice. Num texto cujo conteúdo não podia estar mais de acordo com o que está a ser defendido, Emerson escreve o seguinte:

«Assim como o ar que respiro é extraído dos grandes repositórios da natureza, assim como a luz no meu livro é concedida por uma estrela cem milhões de milhas distante, assim como o equilíbrio do meu corpo depende do equilíbrio de forças centrífugas e centrípetas, assim também as horas devem ser instruídas pelas eras, e as eras pelas horas» ${ }^{24}$.

O que está em causa é, precisamente, a ideia de que cada indivíduo, em cada tempo e em cada lugar, pode fazer do verbo carne. E pode fazê-lo (mais: só pode fazê-lo) de um modo pessoal, isto é, encarnando na sua própria vida os fenómenos latentes nos textos medievais. O mesmo Emerson já havia dito que

tem consequências muito negativas e leva à perda daquilo que a filosofia tem de próprio. De facto, tem sido forte e até mesmo dominante, no ensino e na investigação da filosofia, a tendência para se substituir a análise de problemas (o confronto com eles, a tentativa do seu esclarecimento, etc.) por indagações sobre as análises feitas no passado, os seus desenvolvimentos ao longo do tempo, a forma como se influenciaram entre si, etc. Não se contesta a legitimidade de uma investigação puramente histórica, nem o grande interesse de que efectivamente se pode revestir. Mas é inaceitável a confusão entre abordagens puramente históricas e a própria investigação filosófica enquanto tal. [...] Numa palavra, a ocupação histórica com empreendimentos filosóficos desenvolvidos por outrem pode e tende a constituir um alibi para a ausência de pensamento próprio - sem o qual pura e simplesmente não há filosofia».

24 Emerson, Emerson Essays and Representative Men (Londres e Glasdow: Collins, 1910), 2. 
«Há uma mente comum a todos os homens. Cada homem é uma enseada para o mesmo e para tudo do mesmo. Quem é admitido uma vez ao direito da razão torna-se um homem livre para todo o Estado. O que Platão pensou, ele pode pensá-lo; o que um santo sentiu, ele pode senti-lo; o que em qualquer momento aconteceu a qualquer homem, ele pode compreendê-lo» ${ }^{25}$.

Ao assumir-se estas palavras como próprias, está-se a sustentar a possibilidade de fazer filosofia medieval sem se abandonar a pátria. Vai-se ainda mais longe, e defende-se a possibilidade de não se abandonar a casa concreta dentro da pátria abstrata. O mesmo é dizer que a leitura fenomenológica se mantém na perspetiva própria - provavelmente a única que existe, ainda mais provavelmente a única à qual se tem acesso. $\mathrm{O}$ acercamento ao texto medieval parte e mantém-se sempre na experiência singular, nas situações normais, correntes, corriqueiras, que constituem a existência de quem lê.

Este método não implica cair no subjetivismo. Como se está a ver, o modelo passa por encarnar fenómenos. E os fenómenos, pelo facto de serem fenómenos, visam sempre o universal. Pode-se dizer que a leitura fenomenológica vai na pista do universal humano - isto é, vai no encalço dos fenómenos universais ou universalizáveis descortinados na existência vulgar de quem investiga. De um modo ou de outro, tudo passa por quem investiga - e só por quem investiga, na relação com os textos. O fenomenólogo não considera, portanto, qualquer coisa como «a mente dos filósofos medievais» - por exemplo, «Agostinho nas suas próprias palavras» ${ }^{26}$ ou «Agostinho no seu contexto» ${ }^{27}$. Diga-se de forma radical: para o fenomenólogo, não existe nem um ponto de vista alheio nem mundos passados. Existe uma perspetiva própria que anseia por compreender um determinado problema, o qual nem é propriedade de um filósofo medieval nem vigora em qualquer coisa como um mundo passado. Trata-se de um problema que - apesar de ter sido identificado e/ou descrito por alguém, segundo determinadas categorias históricas - é universal ou universalizável. Quem está em jogo é, portanto, «apenas» um explorador que se mantém no seu país e que, a partir dos textos, encontra fenómenos próprios de toda e qualquer fauna pelo mero facto de ser uma fauna.

Todos os tipos de leitura acarretam consequências não só positivas mas também negativas. O modelo fenomenológico tem «ângulos mortos». Não se nega este facto. Contudo, partilha-se da convicção de Paula Oliveira e Silva

25 Emerson, Emerson Essays and Representative Men, 1.

26 Cfr., por exemplo, William Harmless (ed.), Augustine In His Own Words (Washington DC: The Catholic University of America Press, 2010).

27 Cfr., por exemplo, Kermit Scott, Augustine - His Thought in Context (Nova Iorque e Mahwah: Paulist Press, 1995). 
segundo a qual a abordagem histórica já fez escola desde o século XIX até meados do século $X^{28}$. E acrescenta-se que também a leitura psicológica já foi feita praticamente até à exaustão. Isto é particularmente visível, uma vez mais, em Agostinho. Posto que os caminhos da filosofia são vastos e a perder de vista, propõe-se uma leitura do texto medieval distinta da corrente. Sempre no convencimento de que: (i) não é o único caminho possível; (ii) mas é um caminho pouco desbravado pelos medievalistas. Admite-se, sem qualquer receio, a possibilidade de a forma mista de acercamento aos textos medievais ser uma chave de inteligibilidade possível (mesmo que, por uma parte, implique uma espécie de esquizofrenia entre aquilo que se lê e aquilo que se vive e, por outra, não corresponda a uma leitura estritamente filosófica). O que não se admite, sob nenhuma perspetiva, é que a psicologia e a história (cruzadas ou em separado) sejam as únicas chaves de inteligibilidade possíveis. Não se lhes reconhece o monopólio da interpretação. E a verdade é que os estudos medievais, mormente os estudos augustinianos, insistem nesta orientação. Por exemplo: quando Kurt Flasch afirma que a distinção radical entre a história e a filosofia é «pedante», está a instituir um monopólio onde ele não deve existir, a menos que seja racionalmente fundado e fundamentado. Para isso, terá de provar, antes de mais, que o seu método de cruzamento é mesmo viável. Depois (mas só depois), poderá reputar os argumentos contrários de «pedantes». E repita-se: terá de dar razões para aquilo que, até esse momento, é uma opinião - e não mais do que uma opinião.

Mas poder-se-ia objetar: se é assim, por que motivo é relevante ler autores medievais? Não seria melhor pensar única e exclusivamente «por si»e «a partir de si»? Ao dar-se resposta a esta pergunta, toca-se a essência última do cariz não subjetivista da leitura fenomenológica, tal como ela está a ser apresentada. Imagine-se um livro que segue uma abordagem fenomenológica segundo Agostinho. Nesse livro, o que é que significa o «segundo Agostinho»? A partir do que foi visto, já se sabe aquilo para que aquela expressão não aponta: não aponta para o homem-Agostinho que presenciou a iminência da queda do império. Mas então tem que ver com o quê? O que já foi visto também deixa entrever a resposta: por «segundo Agostinho» entende-se um sistema de sentido possivel para identificar e descrever os fenómenos da existência humana enquanto tal. Por isso, longe de querer explicar o que o homem-Agostinho pensou e disse num tempo distante e num mundo que alegadamente não é o contemporâneo, o fenomenólogo pretende averiguar, nos textos e a partir dos textos, qual é o possivel sentido pessoal para os fenómenos identificados e descritos neles. A leitura fenomenológica corresponde sempre, então, à leitura de um aparato de textos que pode despertar

28 Cfr. Paula Oliveira e Silva, Ordem e Ser - Ontologia da Relação em Santo Agostinho (Lisboa, Centro de Filosofia da Universidade de Lisboa, 2007), 29. 
o sujeito para o acontecimento real e flagrante de si. O ser humano tende a estar adormecido; a perspetiva adormecida tende a vigorar de forma automática (no sentido pascaliano do termo). A proposta de Agostinho, por exemplo - quer dizer, a proposta de um conjunto de textos que constitui no seu todo uma sugestão de sentido -, possibilita o confronto de si consigo próprio. A obra augustiniana surge, assim, como uma possibilidade: uma possibilidade de identificar e descrever os fenómenos que estão sempre já a operar em toda e qualquer existência humana - e que, portanto, correspondem à fauna de um país muito (mas mesmo muito) próximo ${ }^{29}$.

Se Agostinho, por exemplo, corresponde a um conjunto de textos; se os textos filosóficos significam possibilidades de sentido; e se as possibilidades de sentido assentam em fenómenos de índole autobiográfica - então resta concluir que o fenomenólogo vai à obra de Agostinho como quem vai a uma obra que pode explicar a existência própria: o tempo, o mundo, a vida do leitor contemporâneo (e não só) - o universal humano. Segundo a leitura fenomenológica, o fio e o narrador estão eles mesmos imersos no leito do tempo próprio ${ }^{30}$. Os textos não correspondem a monumentos de museu. São antes o pano de fundo de uma peça na qual o leitor representa o papel principal - numa cena que começa sempre medias in res, porque é desempenhada por alguém que já está lançado no curso da existência.

Em última análise, a leitura fenomenológica pretende resgatar o sujeito do sono letárgico em que ele tende a estar mergulhado, tirá-lo da assistência cómoda, como que «empurrá-lo para o palco da vida» - obrigando-o, assim, a produzir (ou melhor: a viver) um pensamento universalmente singular.

Quase a finalizar este artigo, note-se que a própria pena augustiniana alerta para a tendência generalizada de lê-lo nos moldes da fauna. E as palavras a esse respeito não são nada amistosas:

29 Esta mesma metodologia acha-se expressa por Mário Jorge de Carvalho, «Problemas de Confinamento de perspetiva». Todo o artigo é relevante a este respeito, mas importa destacar o seguinte excerto: «Nas condições que efetivamente marcam a nossa capacidade de conceção de perspetivas - dadas as limitações a que está sujeita tal capacidade - os enunciados de outrem (ou pelo menos muitos dos enunciados de outrem) constituem meios de transposição da finitude de ângulo do nosso ponto de vista, pondo no interior do nosso alcance referências a modos de ver que espontaneamente não atingimos» (127-8). E o mesmo autor conclui, na página 133: «Ou seja, a despeito de todos os fatores de restrição de que aqui se tentou dar alguma ideia, os enunciados que nos aparecem com a assinatura de outrem constituem ou podem, de todo o modo, constituir uma espécie de "cavalo de Tróia", introduzindo, no "interior da nossa ótica, como que "embriões" ou "pontas de fios" de algo que se situa para lá dos seus limites».

30 Cfr. José Rosa, O Primado da Relação - Da Intencionalidade Trinitária da Filosofia (Lisboa: Universidade Católica Editora, 2007), 20. 
«Que gente curiosa em conhecer a vida alheia e que indolente em corrigir a sua! Porque querem ouvir de mim o que sou e não querem ouvir de ti o que eles são? E, quando ouvem falar de mim próprio, como sabem se eu digo a verdade, uma vez que nenhum homem sabe o que se passa no homem, a não ser o espírito do homem que está nele próprio» ${ }^{31}$.

Nenhum homem sabe o que se passa no homem - uma tal aproximação tira a perspetiva própria do anonimato, convoca a própria razão a dar uma razão própria de si. Uma obra como as Confissões é, pois, muito mais do que um relato, na terceira pessoa, de alguém que experimentou determinadas coisas durante a sua vida passada. É todo o acontecimento pessoal que se acha sob mira naquele texto filosófico. A perspetiva em jogo é a própria - se é que, repita-se, existe para o leitor mais alguma (algo que o texto acima citado parece questionar). Por isso, no momento de fechar este artigo, pode-se ir à obra de Wittgeinstein para assumir como próprio um dos seus ditos:

«Este livro [no caso, presente, este artigo] será talvez apenas compreendido por alguém que tenha uma vez ele próprio já pensado os pensamentos que são nele expressos - ou pelo menos pensamentos semelhantes. Não é, pois, um livro de texto. O seu fim seria alcançado se desse prazer a quem o lesse compreendendo $»^{32}$.

\section{BIBLIOGRAFIA}

Agostinho. Confessionum Libri Tredecim. Nova Iorque e Londres: Corpus Scriptorum Christianorum Ecclesiasticorum Latinorum, vol. 33, Johnson Reprint Corporation, Nova Iorque e Londres, 1962.

Barbosa, Diogo Morais. "Natura Semper in se Curva» - A Vinculação a Si e a Possibilidade de Desvinculação Segundo Duns Escoto (Porto: Fundação Eng. ${ }^{\circ}$ António de Almeida, 2012).

Fritsch, Matthias e Gosetti-Ferencei, Jennifer Anna. M. Heidegger. The Phenomenology of Religious Life. Bloomington e Indianopolis: Indiana University Press, 2004.

Carvalho, Mário Jorge de. «Problemas de Desconfinamento de Perspectiva - Pensar por Si, o Pensamento de Outrem e Alguns Preconceitos Sobre a Filosofia Actual

31 Agostinho, Conf. X, III, 3, CSEL, XXXIII, 227-8: «curiosum genus ad cognoscendam vitam alienam, desidiosum ad corrigendam suam. quid a me quaerunt audire qui sim, qui nolunt a te audire qui sint? et unde sciunt, cum a me ipso de me ipso audiunt, an verum dicam, quandoquidem nemo scit hominum, quid agatur in homine, nisi spiritus hominis, qui in ipso est?».

32 Wittgenstein, Tratado Lógico-Filosófico (Lisboa: Fundação Calouste Gulbenkian, 1987), trad. Manuel Lourenço, 27. 
e o Passado da Filosofia». Cassiano Reimão (ed.), Os Longos Caminhos do Ser - Homenagem a Manuel Barbosa da Costa Freitas. Lisboa: Universidade Católica Editora, 2003.

Carvalho, Mário Santiago de. A Síntese Frágil - Uma Introdução à Filosofia (Da Patrística aos Conimbricenses). Lisboa: Colibri, 2002.

Dolby, Maria del Carmen. El Hombre Es Imagen de Dios - Visión Antropológica de San Agustín. Pamplona: Eunsa, 2. edição, 2002.

Emerson. Emerson Essays and Representative Men. Londres e Glasdow: Collins, 1910.

Flasch, Kurt. Agostino d'Ippona - Introduzione all'Opera Filosofica. Bolonha: Il Molino, 2002.

Heidegger, Martin. Ser e Tempo. Petrópolis: Vozes, 1988.

Merleau-Ponty, Maurice. Phénoménologie de la Perception. Paris: Gallimard, 1945.

Pascal. Pensées. Paris: Seuil, 1978.

Kant, I. Lisboa: Fundação Calouste Gulbenkian, 6. ${ }^{\mathrm{a}}$ edição, 2008.

Unamuno, Miguel de. Del Sentimento Trágico de la Vida - En los Hombres y en los Pueblos. Madrid: Epasa-Calpe, S. A., 4. ${ }^{\text {a }}$ edição, 1985.

Scott, Kermit. Augustine - His Thought in Context. Nova Iorque e Mahwah: Paulist Press, 1995.

Silva, Paula Oliveira e. Ordem e Ser - Ontologia da Relação em Santo Agostinho. Lisboa: Centro de Filosofia da Universidade de Lisboa, 2007.

William Harmless (ed.). Augustine In His Own Words. Washington DC: The Catholic University of America Press, 2010.

Wittgenstein, L. Tratado Lógico-Filosófico, Lisboa: Fundação Calouste Gulbenkian, 1987.

Xavier, Maria Leonor. Santo Agostinho - Pensar, Conhecer, Ensinar em «De Magistro». Lisboa: dissertação de mestrado, apresentada à Universidade de Lisboa, 1985. 
(Página deixada propositadamente em branco.) 